Check for updates

Cite this: Phys. Chem. Chem. Phys., 2021, 23, 7541

\section{Chemical reactions on surfaces for applications in catalysis, gas sensing, adsorption-assisted desalination and Li-ion batteries: opportunities and challenges for surface science}

\author{
Danil W. Boukhvalov, $\dagger^{\mathrm{ab}}$ Valentina Paolucci, (D) $\dagger^{\mathrm{c}}$ Gianluca D'Olimpio, (D) ${ }^{\mathrm{d}}$ \\ Carlo Cantalini ${ }^{\mathrm{C}}$ and Antonio Politano (D) *de
}

\begin{abstract}
The study of chemical processes on solid surfaces is a powerful tool to discover novel physicochemical concepts with direct implications for processes based on chemical reactions at surfaces, largely exploited by industry. Recent upgrades of experimental tools and computational capabilities, as well as the advent of two-dimensional materials, have opened new opportunities and challenges for surface science. In this Perspective, we highlight recent advances in application fields strictly connected to novel concepts emerging in surface science. Specifically, we show for selected case-study examples that surface oxidation can be unexpectedly beneficial for improving the efficiency in electrocatalysis (the hydrogen evolution reaction and oxygen evolution reaction) and photocatalysis, as well as in gas sensing. Moreover, we discuss the adsorption-assisted mechanism in membrane distillation for seawater desalination, as well as the use of surface-science tools in the study of Li-ion batteries. In all these applications, surface-science methodologies (both experimental and theoretical) have unveiled new physicochemical processes, whose efficiency can be further tuned by controlling surface phenomena, thus paving the way for a new era for the investigation of surfaces and interfaces of nanomaterials. In addition, we discuss the role of surface scientists in contemporary condensed matter physics, taking as case-study examples specific controversial debates concerning unexpected phenomena emerging in nanosheets of layered materials, solved by adopting a surface-science approach.
\end{abstract}

Received 21st June 2020,

Accepted 20th August 2020

DOI: $10.1039 / \mathrm{d} 0 \mathrm{cp} 03317 \mathrm{k}$

rsc.li/pccp catalysis, ${ }^{15-18}$ starting with the pioneering work of Nobel Prize laureate Irving Langmuir on adsorption at surfaces ${ }^{19}$ up to the recent achievements of Nobel Prize laureate Gerhard Ertl, affording a detailed understanding of the surface chemistry of the Haber-Bosch process. ${ }^{20,21}$ The advent of surface science not only increased our fundamental understanding of the properties of condensed matter, but also significantly contributed to the description of complex technologically important phenomena, where the properties of surfaces play a major role. In particular, the investigation of interatomic interactions at surfaces by vibrational spectroscopies, such as high-resolution electron energy loss spectroscopy (HREELS) ${ }^{22-24}$ and inelastic helium atom scattering (HAS), ${ }^{25-37}$ was decisive in the identification of the physicochemical mechanisms governing chemical reactions at surfaces, i.e., adsorption, diffusion, combination of reactants, and desorption. ${ }^{38-40}$ Moreover, scanning tunneling microscopy (STM) enabled the manipulation of atoms and molecules on surfaces, ${ }^{41}$ with the fascinating prospect to trigger chemical reactions. ${ }^{42}$ Surface science has gradually transformed its original phenomenological characteristics into rational tailoring of materials and processes. Experimental methods have drastically improved in their resolution and capabilities, 
with the possibility to follow in real-time surface chemical reactions using both microscopic ${ }^{43,44}$ and spectroscopic ${ }^{45,46}$ tools. Similarly, the advent of operando techniques ${ }^{47-51}$ is abating the long-standing hurdle related to the "pressure gap" 52 between in situ experiments in an ultrahigh vacuum and industrial catalytic processes. ${ }^{53}$ Correspondingly, theoretical models accomplished a huge leap with the unceasing upgrading of computational capabilities, ${ }^{54-58}$ including corrections for taking into account weak forces, ${ }^{59,60}$ now enabling the prediction of chemical properties of surfaces and interfaces. ${ }^{61-64}$

The advent of two-dimensional (2D) materials had a dramatic impact on research of materials, ${ }^{65-71}$ so that most groups working on surface science moved their activities to match the current interests of the scientific community. Nevertheless, surface science should remain at the vanguard of both technological and scientific advances, also considering the higher relevance of surface phenomena in nanostructures. ${ }^{72}$ Though nanoscience inherently represents a giant opportunity and challenge for the surfacescience community, actually the abundant amount of work produced so far on 2D materials often fails in reproducibility, owing to (i) the progressively reduced attention paid to experimental procedures to secure surface cleanliness (including environmental contamination ${ }^{73}$ ), (ii) the use of spectroscopic tools without surface sensitivity, and (iii) the predominance of poorquality commercial samples. ${ }^{74}$ Therefore, the role of the surfacescience community nowadays is particularly demanding. Explicitly, surface scientists should provide convincing and unambiguous proof of the necessity to adopt the rigid protocols of surface science to study surface-related processes on recently emerged nanomaterials, in order to afford their own contribution to avoid misleading interpretations.

Here, we provide a Perspective on recent developments of investigations of chemical processes on surfaces of novel 2D materials and their direct implications in application fields, such as catalysis, batteries, gas sensing and desalination. Especially, we highlight the possibilities arising from the formation of selfassembled heterostructures formed exploiting the natural interaction with air of surfaces of $2 \mathrm{D}$ materials or topological semimetals. Unexpectedly, surface oxidation is beneficial for both catalysis and gas sensing. Moreover, we define the role of surface science in application fields, such as distillation technologies for seawater desalination and Li-ion batteries.

\section{The origin of the electrocatalytic performance in GaSe nanosheets: quantum size effects or surface oxidation?}

The comprehension of electrocatalytic reactions had highly profited from the study of model systems with surface-science spectroscopies. ${ }^{75}$ Especially, the combination of in situ spectroscopic experiments with density functional theory calculations was decisive to establish (i) the mechanisms controlling the reaction paths and (ii) the influence of acidic and alkaline media. ${ }^{76}$

Recently, exfoliation of GaSe in nanosheets has been shown to be beneficial for improving the performance of the hydrogen evolution reaction (HER), ${ }^{77}$ photoelectrochemical water splitting, ${ }^{78}$ and gas sensing. ${ }^{79}$ However, GaSe undergoes oxidation in ambient air with the formation of $\mathrm{Ga}_{2} \mathrm{O}_{3}{ }^{80-88}$ Precisely, most researchers reported complete degradation of GaSe flakes with a thickness of 10-50 nm, although the time required for oxidation is quite controversial, ranging from 30 minutes $^{82}$ up to some days (4 in ref. 89,5 in ref. 90, 8 in ref. 91 , and $>14$ in ref. 92). On the other hand, Rahaman et $a l^{86}$ reported that the penetration of the oxidation has a self-limited depth of only three layers after five hours in air.

As evident from the analysis of X-ray photoelectron spectroscopy (XPS) data in Fig. 1b, GaSe is stable in a vacuum, while air exposure induces the emergence of spectral features related to the $\mathrm{Ga}^{+3}$ oxidation state in $\mathrm{Ga}_{2} \mathrm{O}_{3}$ for both the bulk ${ }^{87,93}$ and nanosheets. ${ }^{81,93}$ Definitely, oxidation proceeds with an intermediate $\mathrm{Ga}_{2} \mathrm{Se}_{3}$-like configuration, with the ultimate emergence of $\mathrm{Ga}_{2} \mathrm{O}_{3}$ for prolonged storage in air. ${ }^{93}$

Actually, the incomplete picture of the physicochemical mechanisms ruling GaSe oxidation should be attributed to the insufficient surface sensitivity of the spectroscopic tools used so far. Indeed, the study of the oxidation state is usually performed using Raman spectroscopy, ${ }^{80,82}$ regardless of its low surface sensitivity, in consideration of its probing depth in the

(a)
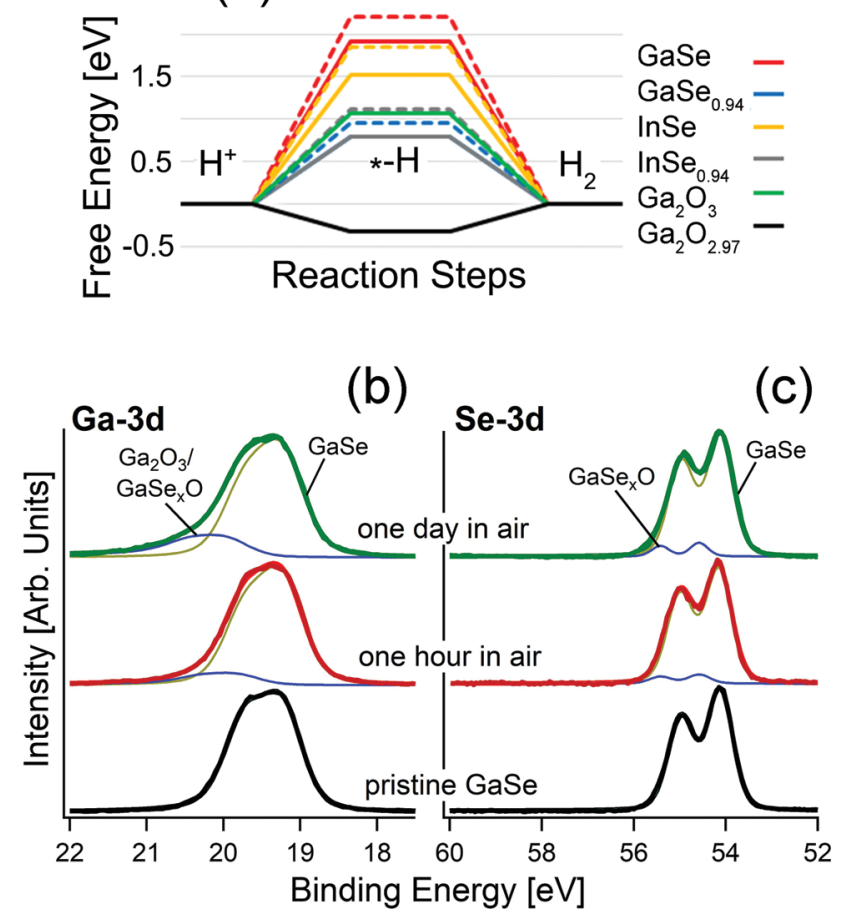

Fig. 1 (a) Free energy diagram for the HER in acidic media over the surface of bulk and monolayer GaSe, GaSe 0.94 , InSe and InSe $\mathrm{S}_{0.94}$ and for the HER over the surface of $\mathrm{Ga}_{2} \mathrm{O}_{3}$ and $\mathrm{Ga}_{2} \mathrm{O}_{2.97}$. Results for monolayers are depicted by dashed lines. Note that the line for the free energy for $\mathrm{GaSe}_{0.94}$ is overlapped with that associated with $\operatorname{InSe}_{0.94}$. Adapted with permission from data in ref. 93. Panels (b) and (c) report core-level spectra for (b) Ga-3d and (c) Se-3d for pristine GaSe and the same surface kept in air for one hour and one day, respectively. 
300-650 nm range. ${ }^{94,95}$ Accordingly, the early steps of oxidation of GaSe-based systems, as well as their corresponding impact on surface chemical reactions in electrochemical, photocatalytic and gas-sensing processes, are generally undetected, owing to insufficient surface sensitivity.

Another important issue is related to the impact of the chemical reactivity of Se vacancies. ${ }^{96}$ Actually, most single crystals of GaSe are far from being stoichiometric. Typically, the $[\mathrm{Ga}]:[\mathrm{Se}]$ ratio ranges from $50.4: 49.6^{97}$ up to $59.1: 40.9^{78}$ even for nominal GaSe samples. Subsequently, the abundant amount of Se-vacancy sites could - at least in principle - play an important role in electrocatalytic and photocatalytic performances reported in ref. 78 and attributed to the exfoliation in nanosheets.

Similar argumentation is also valid for the case of the parental compound InSe. ${ }^{93}$

Remarkably, calculated values of the free energies for the HER (Fig. 1a) evidence unsuitability of bulk GaSe and its parental compound InSe for this reaction, with energy barriers as high as 1.9 and $1.5 \mathrm{eV} / \mathrm{H}^{+}$, respectively. The presence of Se-vacancies in both GaSe and InSe significantly decreases the energy cost of the process ( 1.5 and $0.7 \mathrm{eV} / \mathrm{H}^{+}$, respectively), but the magnitude is still quite larger than for the $\operatorname{Pt}(111)$ surface $\left(0.1 \mathrm{eV} / \mathrm{H}^{+}\right)$, usually taken as a standard reference (Fig. 1a). ${ }^{98} \mathrm{In}$ the case of free-standing monolayers, the values of the energy cost of the HER are even larger: 2.2 and $1.8 \mathrm{eV}$ for GaSe and InSe, respectively. Therefore, the common picture that liquidphase exfoliation of GaSe and InSe favors the improvement of the HER performance on the basis of the higher amounts of edges behaving as active sites, recently proposed in ref. 78 and 99, should be revised. On the contrary, the calculated values for $\mathrm{Ga}_{2} \mathrm{O}_{3}$ and the sub-stoichiometric oxide $\mathrm{Ga}_{2} \mathrm{O}_{2.97}$ are 1.1 and $-0.3 \mathrm{eV} / \mathrm{H}^{+}$. Therefore, for $\mathrm{Ga}_{2} \mathrm{O}_{2.97}$ the Heyrovsky step $\left(\mathrm{H}_{\mathrm{ads}}+\right.$ $\mathrm{H}^{+}+\mathrm{e}^{-} \rightarrow \mathrm{H}_{2}$ ) of the HER is exothermic.

In the case of the oxygen evolution reaction (OER), in both acidic and alkali media, the second step of the OER, which involves the formation of $-\mathrm{O}$ groups on the substrate, has highly negative values of free energy $(-5.7$ and $-7.4 \mathrm{eV}$ for GaSe and $\left.\mathrm{GaSe}_{0.94}\right)$, owing to the favorability of GaSe oxidation. Thus, the surface of bulk GaSe will be irreversibly oxidized during the OER in both acidic and alkali environments. ${ }^{93}$

Therefore, the literature data on electrocatalysis and photocatalysis based on GaSe should be re-interpreted. Especially, we note that, in the survey of the electrochemical properties of GaSe by Tan et al., ${ }^{100}$ the authors assume from XPS analysis that the surface composition of GaSe is more complex with respect to the theoretical one, considering the non-stochiometric [Ga]: $[\mathrm{Se}]$ ratio and the presence of oxygen contaminants. The lowest Tafel slope (150 $\mathrm{mV} \mathrm{dec}^{-1}$ ) in the HER was found in nominally reduced GaSe, for which the authors claimed the removal of the passivation layer of $\mathrm{Ga}_{2} \mathrm{O}_{3}$, supposed to poison active sites of the GaSe surface. However, surface treatments such as those in ref. 100 are expected to promote the formation of sub-stoichiometric $\mathrm{Ga}_{2} \mathrm{O}_{3-x}$ phases, which represent a good platform for the HER.

Recently, liquid-phase exfoliated GaSe nanosheets have been used $^{78}$ to produce photoelectrodes exhibiting catalytic activity toward water splitting reactions, i.e., the HER and OER. Based on the results in Fig. 1a, it is evident that the role of GaSe in photochemical water splitting is just to generate electron-hole pairs via light harvesting, while the $\mathrm{Ga}_{2} \mathrm{O}_{3}$ skin represents the only chemically active part of the photoelectrode. On the other hand, the presence of $\mathrm{Ga}_{2} \mathrm{O}_{3}$ in GaSe samples in ref. 78 can be clearly identified from the analysis of Raman, ultraviolet photoemission spectroscopy (UPS) and XPS experiments, with oxidation particularly favored by the largely non-stoichiometric [Ga]:[Se] ratio of $59.1: 40.9$.

\section{The origin of the HER performance in $\mathrm{PtSn}_{4}$ : topological states or surface oxidation?}

The connection between topologically nontrivial electronic states and catalytic activity has been recently claimed by different groups. ${ }^{101-106}$ Among various topological materials, Pt-based topological systems are particularly relevant for catalytic applications, due to the wide use of Pt in several catalytic reactions, including the HER ${ }^{107}$ and OER. ${ }^{108}$ Recently, it has been reported that $\mathrm{PtSn}_{4}$ has outstanding performance in the HER, ${ }^{104}$ ascribed to (i) the existence of topological Dirac node arcs reported in ref. 109 and (ii) the supposed occurrence of a Pt skin, i.e. an atomic Pt layer as surface termination, which is just assumed by the authors to exist in analogy with other Pt-based alloys. ${ }^{110-112}$

Considering the standard pathway of the HER, i.e. the (i) Volmer $\left(\mathrm{H}^{+}+\mathrm{e}^{-} \rightarrow \mathrm{H}_{\mathrm{ads}}\right)$, and (ii) Heyrovsky $\left(\mathrm{H}_{\mathrm{ads}}+\mathrm{H}^{+}+\right.$ $\mathrm{e}^{-} \rightarrow \mathrm{H}_{2}$ ) steps, theoretical results (Fig. 2a) demonstrate that the energy cost of the Heyrovsky step is rather large for both Ptand $\mathrm{Sn}$-terminated $\mathrm{PtSn}_{4}$ surfaces (0.75 and $0.84 \mathrm{eV}$ ), in contrast with experimental results. ${ }^{104}$

A completely different scenario is enabled by surface oxidation. Given the combination of the (i) Volmer and (ii) Tafel $\left(2 \mathrm{H}_{\mathrm{ads}} \rightarrow \mathrm{H}_{2}\right)$ steps, in the case of an oxidized Sn-terminated surface, hydrogen atoms bond to oxygen atoms with the formation of hydroxyl groups. In this process, the Tafel step does not represent the migration of the unbound adatom on the surface, but instead it is related to the migration of hydrogen from one oxygen atom to another. Considering (i) that the distance between oxygen atoms in the oxidized Sn-terminated surface is about $0.2 \mathrm{~nm}$ (less than in any other metal) and (ii) the existence of charge transfer from the Pt-sublayer, the energy cost of hydrogen migration results to be only $0.2 \mathrm{eV}$, i.e., comparable with the energy cost of the Heyrovsky reaction for $\mathrm{Pt}(111)$. Thus, one can conclude that the contribution from topological states in the electro-catalytic performance of $\mathrm{PtSn}_{4}$ is negligible, ${ }^{113,114}$ while surface oxidation plays an unexpectedly beneficial role for the HER. ${ }^{113,114}$

Correspondingly, the Tafel slope measured in electrocatalytic tests is reduced from $\sim 442$ to $\sim 86 \mathrm{mV} \mathrm{dec}{ }^{-1}$ upon oxidation treatment (Fig. 2b).

XPS experiments (Fig. 2c and d) confirm the transformation of the surface upon air exposure with two spectral components appearing in the Sn-3d core-level spectra (Fig. 2d), arising from SnO (binding energy, BE, of $\sim 486.2 \mathrm{eV}$ ) and $\mathrm{SnO}_{2}(\mathrm{BE}$ of $\sim 487.2 \mathrm{eV}$ ) species. ${ }^{115}$ Especially, the $\mathrm{SnO}_{2}$ component (Fig. 2b) 

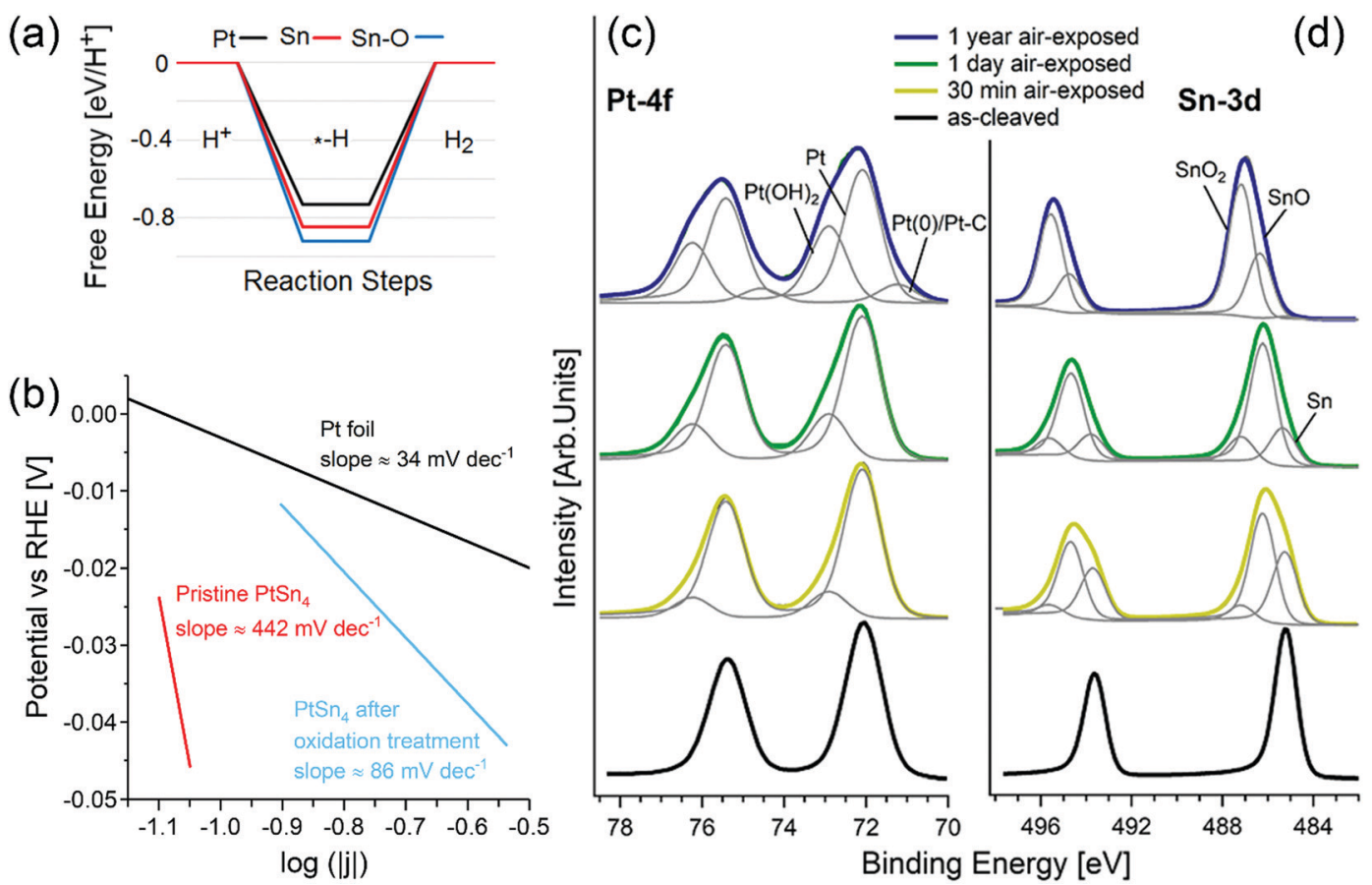

Fig. 2 (a) Free energy diagrams for the HER on pristine, oxidized Pt-terminated and Sn-terminated surfaces of PtSn after the treatment at $1.035 \mathrm{~V}$ vs. RHE, registered at $1 \mathrm{mV} \mathrm{s}^{-1}$. The reference curve for Pt is also reported. Panels (c) and (d) show core-level spectra for (c) Pt- $4 \mathrm{f}$ and (d) Sn-3d for pristine PtSn 4 and the same surface kept in air for $30 \mathrm{~min}, 24 \mathrm{~h}$, and one year. The photon energy is $800 \mathrm{eV}$ and the spectra are normalized to the maximum. Adapted with permission from ref. 113.

gradually increases from $5 \%$ (after $30 \mathrm{~min}$ in air) to $13 \%$ (after $24 \mathrm{~h}$ in air) and finally to $65 \%$ (after 1 year in air) with the corresponding disappearance of $\operatorname{Sn}(0)$ species. On the other hand, the spectrum of Pt-4f core levels (Fig. 2c) acquired for the $\mathrm{PtSn}_{4}$ surface kept 30 minutes in air shows a new component at $\mathrm{BE} 72.95 \mathrm{eV}$ ascribable to $\mathrm{Pt}(\mathrm{OH})_{2}{ }^{116,117}$ or $\mathrm{Pt}-\mathrm{O}$ units $^{115}$ in an early stage oxidation of $\mathrm{Pt}$ atoms. Correspondingly, the thickness of the tin-oxide layer $\mathrm{SnO}+$ $\mathrm{SnO}_{2}$ ) formed on the sample left in an ambient atmosphere increases from $9 \pm 1 \AA$ (30 min in air) up to $36 \pm 5 \AA$ (1 year in air).

\section{Materials engineering and photocatalysis: the role of surface science}

Surface science gave a huge contribution in the comprehension of bulk, surface and interfacial phenomena in photocatalysis. ${ }^{118,119} \mathrm{~A}$ typical application of photocatalysis is related to solar energy harnessing, ${ }^{120}$ which uses semiconductors for solar energy conversion into chemical energy, ${ }^{121}$ promoting redox reactions at over-surface catalytic sites by means of the separation of photogenerated electron-hole pairs. ${ }^{122}$ Although a large variety of photocatalysts were explored, ${ }^{123-125}$ some crucial drawbacks typically drop down their performances. For example, the light absorption provided by the most studied photocatalytic semiconductor, $\mathrm{TiO}_{2}$, is limited in the range of the ultraviolet spectrum, owing to its bandgap of $3.0-3.4 \mathrm{eV} .^{126}$ Moreover, another typical problem arising from traditional photocatalysts is represented by the recombination of electron-hole pairs during charge transport. ${ }^{127}$ It can be related either to the low mobility of photoinduced carriers or to the charge carriers not being consumed by surface reactions, because of the low number of catalytic sites at the surface. ${ }^{128}$

Especially, photocatalysis with 2D materials has attracted considerable interest for their peculiar physicochemical properties, ${ }^{129-131}$ considering the high surface-to-volume ratio of nanosheets, with intrinsically high amounts of active sites for catalytic reactions. Moreover, when the thickness is reduced to the nanoscale, the photo-induced charge carriers can move from the bulk to the surface in a short distance. This reduction in traveling length inhibits the electron-hole recombination during charge transport and allows more charge carriers to be preserved for surface reactions.

Nevertheless, the interpretation of the mechanisms governing the photocatalytic activities was traditionally limited to electrochemical properties and band-structure models. ${ }^{132}$ On the other hand, the use of surface-science techniques could provide useful insights for a detailed comprehension of the photocatalytic processes. ${ }^{133}$ Researchers focused their attention on the modification of $2 \mathrm{D}$ materials for improving the photocatalytic efficiency, including the design of the structure and morphology, ${ }^{134,135}$ doping and vacancy engineering, ${ }^{136}$ and integration with other semiconductors or metals. ${ }^{137,138}$ Surface science can play a pivotal role in terms of the analysis of photoactive sites and to unveil reaction mechanisms and intermediates, as well as the optimal operational conditions to get the final conversion. ${ }^{118}$

Recently, several studies have been published regarding the influence of the controlled oxidation of transition-metal dichalcogenides on photocatalysis, especially in the field of solar 


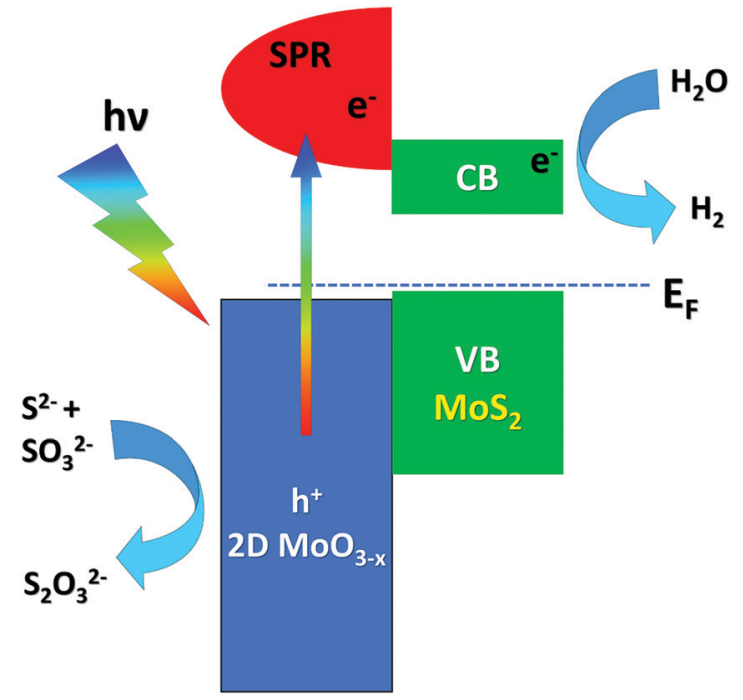

Fig. 3 Energy-level alignment and the mechanism of electron transfer at the $\mathrm{MoS}_{2} / \mathrm{MoO}_{3}$ interface. Adapted with permission ref. 141. CB and VB stand for the conduction and valence band, respectively.

energy production. ${ }^{139-141}$ In particular, Patra et al. ${ }^{141}$ synthesized a $\mathrm{MoS}_{2} / \mathrm{GO}$ (with GO being graphene oxide) composite by a hydrothermal process and with subsequent $\mathrm{MoS}_{2}$ oxidation by calcination at different temperatures under an $\mathrm{N}_{2}$ atmosphere, which promotes the diffusion of atomic oxygen from the GO layer to the $2 \mathrm{D} \mathrm{MoS}$ layer, resulting in a $\mathrm{MoO}_{3-x} / \mathrm{MoS}_{2}$ heterojunction, with the non-stoichiometric $2 \mathrm{D} \mathrm{MoO}_{3-x}$ exhibiting a surface plasmon resonance (SPR) with a frequency matching the solar spectrum. ${ }^{142}$ The observed enhanced photocatalytic activity is ascribed to the oxidation of $\mathrm{Mo}^{4+}$ cations of $\mathrm{MoS}_{2}$ to higher oxidation states $\left(\mathrm{Mo}^{5+}\right.$ and $\mathrm{Mo}^{6+}$ in $\left.\mathrm{MoO}_{3-x}\right)$, which also modifies the valence-band (VB) electronic structure and the work function of the $\mathrm{MoO}_{3-x} / \mathrm{MoS}_{2} / \mathrm{rGO}$ composite (with rGO being reduced GO), as demonstrated by XPS and UPS experiments. The presence of $2 \mathrm{D} \mathrm{MoO}_{3-x}$ layers with a large amount of $\mathrm{Mo}^{5+}$ oxidation states allows easier carrier generation due to SPR generation, while $\mathrm{MoS}_{2}$ offers active sites for catalysis (Fig. 3). Solar $\mathrm{H}_{2}$ generation (SHG) was proved in the near-infrared and the visible region by combining plasmonic and catalytic effects in the composite.

\section{Gas sensing in van der Waals semiconductors: the role of surface oxidation}

Gas sensors for environmental detection of sub-ppb concentrations of noxious gas like $\mathrm{CO}, \mathrm{NO}_{2}, \mathrm{H}_{2} \mathrm{~S}$, and $\mathrm{H}_{2}$ are based on catalytic materials, which modulate their electrical properties, due to complex redox reactions taking place between the target gas and the surface termination of the investigated sensing materials. ${ }^{143}$ Van der Waals semiconductors promise new perspectives for gas sensing applications beyond state-of-the-art porous metal-oxide sensors, ${ }^{144}$ due to their (i) high surface-to-volume ratio, (ii) intrinsically large amount of active sites for catalytic reactions, (iii) no residual porosity and (iv) reduced charge transfer travelling length, which enhance the amount of charge carriers for surface reactions. ${ }^{145}$ As for metaloxide sensors, ${ }^{144}$ van der Waals semiconductor-based sensors are generally heated at mild operating temperatures $\left(T<150{ }^{\circ} \mathrm{C}\right)$ to avoid irreversible desorption of the target gas at low temperature, leading to surface oxidation in the case of metal chalcogenides, including transition-metal dichalcogenides. ${ }^{146}$ Remarkably, this issue has been regarded so far as a significant drawback, limiting the application of van der Waals semiconductor-based sensors. However, unexpectedly, the spontaneous oxidation of metal chalcogenides ${ }^{147}$ opens new outlooks for gas sensing applications. Here, we focus on the case-study example of tin diselenide $\left(\mathrm{SnSe}_{2}\right)$, a van der Waals semiconductor with high electron mobility $\left(462.6 \mathrm{~cm}^{2} \mathrm{~V}^{-1} \mathrm{~s}^{-1}\right.$ at $\left.T=300 \mathrm{~K}^{148}\right)$, which has been recently reported to be a suitable material for the detection of $\mathrm{NO}_{2}{ }^{149,150}$ and $\mathrm{NH}_{3},{ }^{151,152}$ in a nitrogen background carrier gas, as well as $\mathrm{CH}_{4}{ }^{153}$ and humidity in dry air. ${ }^{151,152}$ The presence of Se vacancies triggers oxidation of the surface in oxidative environments (including air), with the emergence of a $\mathrm{SnO}_{2}$ surface layer, with sub-nanometric thickness, ${ }^{154}$ whose presence is evident in HREELS analysis (Fig. 4). The formed $\mathrm{SnO}_{2}$ skin is amorphous, as indicated by the disappearance of diffraction peaks in the low-energy electron diffraction pattern. ${ }^{154}$

Density functional theory results indicate that $\mathrm{SnO}_{2} / \mathrm{SnSe}_{2}$ is more sensitive to chemisorbed species with respect to the pristine $\mathrm{SnSe}_{2}{ }^{154}$ As a matter of fact, $\mathrm{H}_{2} \mathrm{O}, \mathrm{NO}_{2}$ and $\mathrm{H}_{2}$ adsorption yield no substantial effect on both the electronic structure and charge densities (Fig. 5) of pristine $\mathrm{SnSe}_{2}$, which turns out

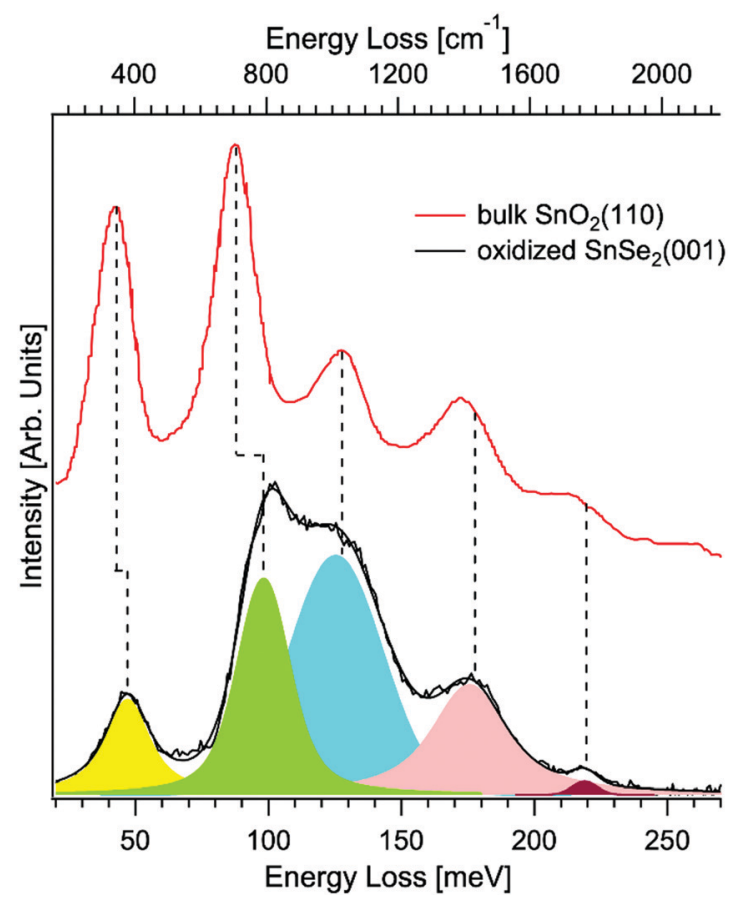

Fig. 4 Vibrational spectra for the oxidized surface of $\mathrm{SnSe}_{2}(001)$ taken by HREELS. The primary electron beam energy is $4 \mathrm{eV}$. Experiments were carried out at room temperature. For the sake of comparison, we report also data for bulk $\mathrm{SnO}_{2}(110)$ (data taken from ref. 155). Reproduced with permission ref. 154. 


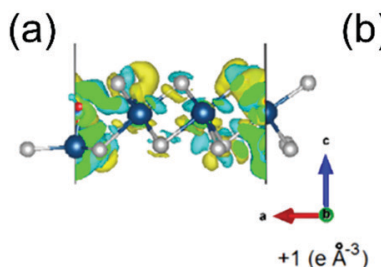

(b)

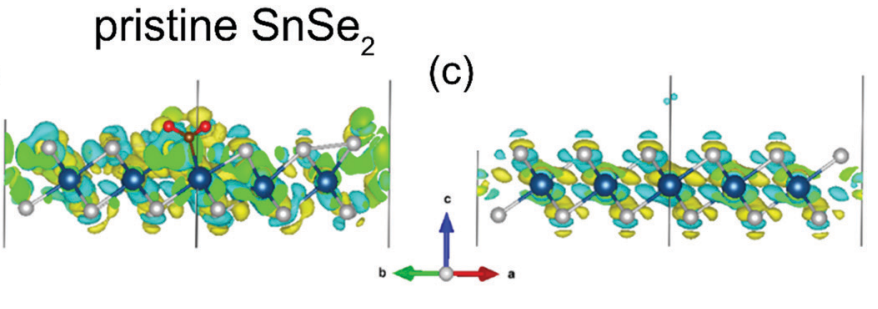

(d)
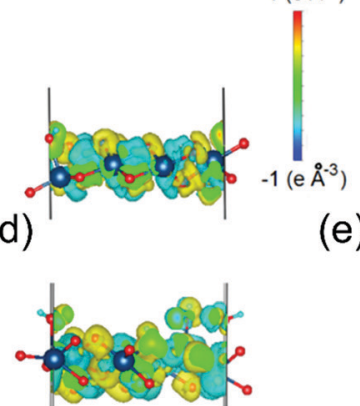

(e)

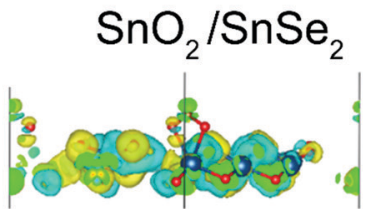

)

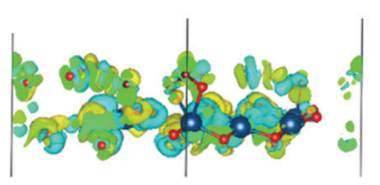

(f)
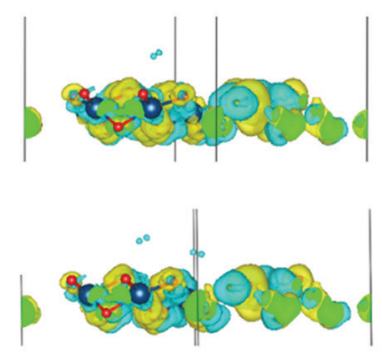

Fig. 5 Changes in the charge densities in ( $a-c) \mathrm{SnSe}_{2}$ or (d-f) $\mathrm{SnO}_{2}$ surfaces after adsorption of ( $a$ and d) water, (b and e) nitrogen dioxide and (c and f) hydrogen. For the $\mathrm{SnO}_{2}$ skin, results for adsorption of a single molecule are shown in the top layer and for the pair of molecules in the bottom layers of the panels. Blue, white and red balls denote Sn, Se, and O atoms, respectively. Reproduced with permission ref. 154.

to be unsuitable for gas sensing applications. Conversely, adsorption of $\mathrm{H}_{2} \mathrm{O}$ and $\mathrm{NO}_{2}$ molecules on the $\mathrm{SnO}_{2} / \mathrm{SnSe}_{2}$ heterostructure shows opposite effects on the electronic structure and charge densities, thus validating the $\mathrm{SnO}_{2} / \mathrm{SnSe}_{2}$ heterostructure for humidity and gas sensing applications.

To validate the theoretical calculations, the $\mathrm{SnO}_{2} / \mathrm{SnSe}_{2}$ heterostructure was exposed to $\mathrm{NO}_{2}$ (400 ppb-1.5 ppm range) and $\mathrm{H}_{2}$ (5-100 ppm range) under a dry air carrier gas (to simulate conditions for environmental sensing) at an operational temperature of $150{ }^{\circ} \mathrm{C}$ (Fig. 6), which enables complete and fast baseline recovery after gas exposure/release cycles. Specifically, $\mathrm{SnO}_{2} /$ $\mathrm{SnSe}_{2}$ shows detection limits of $400 \mathrm{ppb}$ and $5 \mathrm{ppm}$ with sensitivities of $(1.06 \pm 0.03)$ and $(0.43 \pm 0.02)[\mathrm{ppm}]^{-1}$ for $\mathrm{NO}_{2}$ and $\mathrm{H}_{2}$, respectively. ${ }^{154}$

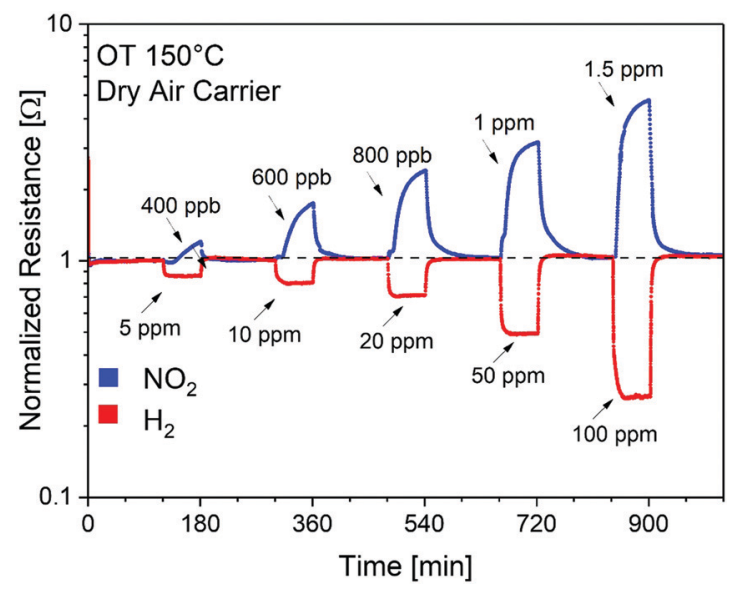

Fig. 6 Dynamic gas responses of the $\mathrm{SnO}_{2} / \mathrm{SnSe}_{2}$ heterostructure for gas concentrations of $\mathrm{NO}_{2}(400 \mathrm{ppb}-1.5 \mathrm{ppm})$ and $\mathrm{H}_{2}(5-100 \mathrm{ppm})$ in a dry air carrier gas at an operational temperature of $150{ }^{\circ} \mathrm{C}$. OT stands for operational temperature. Reproduced with permission ref. 154.

\section{Adsorption-assisted desalination: membrane technology meets surface science through adsorption}

Here, we will highlight the relevance of surface phenomena in emerging desalination techniques. Freshwater availability is one of the major challenges that our society is facing, due to the progressive demographic expansion, climate change and desertification. ${ }^{156}$ Correspondingly, the World Health Organization (WHO) evidenced an alarming scenario: $c a$. 50\% of the world's population will be living in water-stressed regions by $2025 .{ }^{157}$ Evidently, seawater desalination represents the most reliable and economically sustainable way to produce drinking and reusable water, considering that seawater constitutes more than $97 \%\left(\sim 1.4 \times 10^{9} \mathrm{~km}^{3}\right)$ of the total water resources. ${ }^{158-160}$ Among the different existing desalination technologies, it is possible to differentiate processes based on (i) evaporation (phase change) and (ii) membranes (non-phase change). ${ }^{161}$ However, the widespread applications of these desalination processes, such as multi-effect distillation (MED) and seawater reverse osmosis (SWRO), require significant energy power, thus limiting their viability in developed countries. In recent years, membrane distillation (MD) has emerged as a promising alternative or as a complementary unit to SWRO. MD is a thermallydriven membrane operation based on the use of microporous hydrophobic membranes. ${ }^{162}$ The hydro-repellent nature of the membrane prevents the permeation of liquids, while sustaining a vapour-liquid interface at the entrance of each pore, where water evaporation takes place. Under a temperature gradient, a net diffusive flux of vapour is observed from the hot feed (Fig. 7a). Here, we take graphene as a case-study example to highlight the role of surface science in the adsorption-assisted MD in polyvinylidene fluoride (PVDF) membranes with graphene fillers. ${ }^{163}$ Explicitly, 

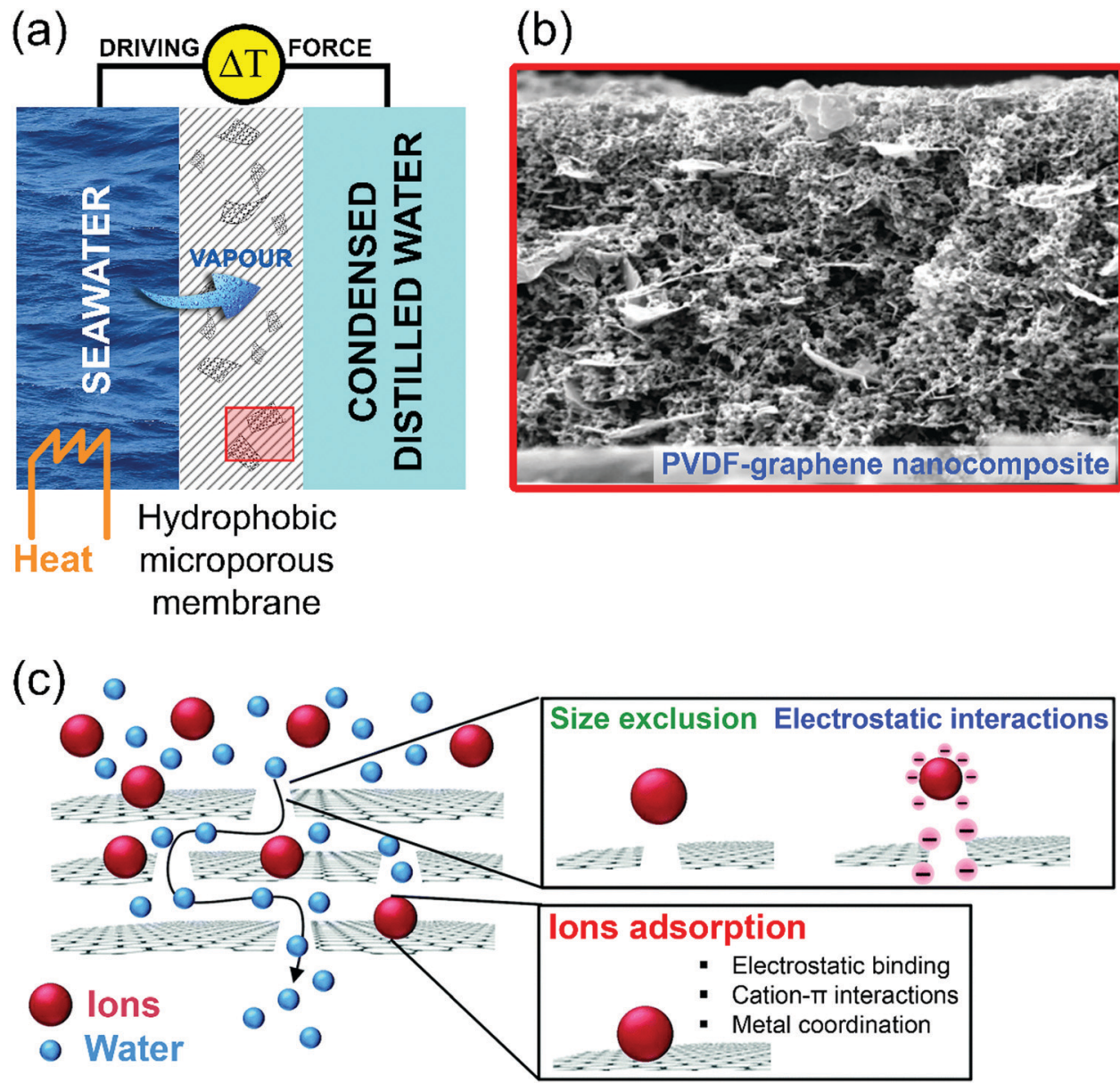

Fig. 7 (a) Schematic illustration of the membrane distillation process. Water vapour passes through the pores of a hydrophobic microporous membrane. (b) Representative SEM micrographs of the cross section of PVDF-graphene composite membranes. Reproduced with permission ref. 163. (c) Schematic representation of the working mechanisms of adsorption-assisted MD in PVDF-graphene nanocomposite membranes. Reproduced with permission ref. 164.

penetration and diffusion of water molecules through free gaps between graphene platelets and the polymer take place via intermolecular interactions at defect sites (Fig. 7b and c). On the other hand, the local arrangement of platelets can affect nearby interactions, causing increased or reduced vapour diffusion. Even with a low amount of filler in the polymer matrix, adhesive interactions are activated at the water/graphene platelet interface, resulting in assisted vapour transport. A further increase in the concentration of the filler can cause massive water uptake over the space between the graphene platelets and the polymer network, thus resulting in potential competition between adhesive and cohesive forces, which causes the penetrant to extend its permanence inside of the membrane. This hypothesis is verified by the occurrence of a transient state in each experiment in ref. 163, carried out with membranes at different loading of graphene platelets. When the concentration of graphene platelets is significantly increased, a longer time is required for collecting water at the permeate side. Even four running hours are required in ref. 163 to observe the onset of permeation of water vapour through the membrane, thus suggesting a longer permanence of the penetrant inside the matrix. A reasonable explanation could arise from the occurrence of intermolecular interactions (Fig. 7c), assisting water to form a wetting layer covering the free gaps between the polymer and the graphene platelets. Consequently, one can conclude that intermolecular water-graphene interactions may assist or inhibit diffusion of water molecules through the membranes depending on the concentration of graphene platelets. Based on experimental findings, ${ }^{163}$ a graphene concentration of $0.5 \%$ is able to promote well-balanced kinetics of adsorption-desorption of the penetrant, leading to assisted transport. A massive concentration of graphene platelets yields a considerable amount of stagnant water, resulting in slowed down transport. As a result, graphene platelets could bring benefits to water vapour transport through membranes equipped in MD plants when their amount and rearrangement in the matrix are well equilibrated.

\section{A surface science approach for Li-ion batteries}

Li-ion batteries generate and store electric power from the electrochemical redox reactions between the electrode materials. In Li-ion batteries, the interface between the active material constituting the electrode and the electrolyte is particularly relevant, 
due to the transfer of lithium ions causing the electrode redox reaction. ${ }^{165}$ Especially, the chemical reactions and charge transfer at cathode/electrolyte interfaces influence the performance and the stability of Li-ion cells. Definitely, the corrosion of the active electrode and the decomposition of the electrolyte are closely coupled to charge transfer reactions at the electrode/ electrolyte interfaces, which are connected to the energy barriers for electrons and ions.

The comprehension of the surface structure, the electronic structure, and chemical reactions at the electrode-electrolyte interface is crucial in order to improve the battery performance. However, the interface is located between the electrode and electrolyte materials, hindering the experimental analysis of the interface. Thus, the physicochemical properties and processes remain largely unclear.

In addition, the investigation of the structural properties of the surface of electrode materials is also particularly relevant. As a matter of fact, the break in crystalline periodicity at the interface strongly influences the interfacial physicochemical properties. The stability of the surface structure of the electrode material strongly depends on the plane orientation. Moreover, the electronic structure is significantly influenced by the termination structure. Experimentally, surface structures were studied only for $\mathrm{LiCoO}_{2}(001),{ }^{166} \mathrm{LiFePO}_{4}(010),{ }^{167} \mathrm{Li}_{4} \mathrm{Ti}_{5} \mathrm{O}_{12}(111){ }^{168}$ $\mathrm{LiTi}_{2} \mathrm{O}_{4}(111),{ }^{169}$ and the basal plane of graphite. The investigation of electronic structures is just limited to the cases of $\mathrm{LiCoO}_{2}(001){ }^{166}$ and $\mathrm{LiTi}_{2} \mathrm{O}_{4}(111) .{ }^{169}$ The physicochemical properties of the surfaces of electrode materials with high activity for $\mathrm{Li}$ insertion and extraction, such as $\mathrm{LiCoO}_{2}(104)$ and the edge plane of graphite, remain poorly understood. Recently, calculations demonstrated that the electronic structures of several $\mathrm{LiCoO}_{2}$ surface facets are significantly different from those of bulk $\mathrm{LiCoO}_{2}$, due to altered spin states of surface $\mathrm{Co}^{3+}$ atoms. ${ }^{170}$

Another issue related to Li-ion batteries that can be addressed only by means of surface-science experiments is related to the initial stages of the interactions between lithium and metal oxides. The study of the initial stages of adsorption of $\mathrm{Li}$ on the $\mathrm{TiO}_{2}$ surface by STM, ${ }^{171}$ metastable-induced electron spectroscopy (MIES) and UPS ${ }^{172}$ and the electron-stimulated desorption approach $^{173}$ evidences the occurrence of metastable adsorption on the defect-free (110) surface and the importance of oversurface defect sites for further penetration of $\mathrm{Li}$ atoms in bulk titania.

Moreover, storage and operation of Li-ion battery electrodes result in electrode surface film formation (solid electrolyte interphase, SEI), which plays an important role in the cell properties and performance. ${ }^{174}$ Such surface films arise from the reactions at the electrode/electrolyte interface (side reactions) and significantly influence the lithium ion transfer. Therefore, surface-science techniques are particularly suitable for investigations of the SEI.

Finally, it is worth mentioning that photoemission spectroscopies can be employed to study ${ }^{174}$ the formation of contact potentials and the alignment of energy levels (for electrons and ions) at interfaces.

\section{Conclusions and outlook}

Here, we selected some case-study examples among 2D materials and novel topological phases of matter to discuss the crucial role of surface science in contemporary research on materials and their related applications. Specifically, we have demonstrated that the inevitable interaction with air should be taken into account when reporting unusual phenomena, erroneously ascribed to quantum size effects arising from exfoliation in nanosheets or to possible connections with the topological band structure. As a matter of fact, the catalytic properties of GaSe and $\mathrm{PtSn}_{4}$ are actually driven by the self-assembled heterostructure formed upon oxidation, while pristine surfaces of $\mathrm{GaSe}$ and $\mathrm{PtSn}_{4}$ are even unsuitable for catalytic applications. Definitely, the metal-oxide skin plays a pivotal role in all processes related to surface chemical reactions. In photocatalysis, the underlying bulk affords electron-hole pairs, while catalytic reactions are uniquely determined by the metal-oxide skin. Similarly, gas sensing in $\mathrm{SnSe}_{2}$-based systems is determined by the formation of an ultrathin $\mathrm{SnO}_{2}$ surface layer.

Moreover, we have elucidated the role of surface-science tools in the analysis of Li-ion batteries and adsorption-mediated distillation techniques in membrane technology for seawater desalination, thus paving the way for a surface-science approach to application fields apparently far from traditional targets of this discipline.

Indeed, surface science is facing an important challenge related to its engagement in contemporary research on physical chemistry, condensed matter physics and materials science. Three obvious possibilities are available for bringing surface science at the vanguard of the scientific community: (i) to use surface systems to model physical concepts relevant for open issues in the literature, concerning both fundamental and applied research; (ii) to adopt experimental methodologies and techniques to avoid misleading interpretation of data in the literature related to poor control of surface phenomena; and (iii) to grow novel interfaces and heterostructures exhibiting exotic effects able to attract the interest of a wide community.

\section{Conflicts of interest}

There are no conflicts to declare.

\section{References}

1 H. J. Freund, N. Ernst, T. Risse, H. Hamann and G. Rupprechter, Phys. Status Solidi A, 2001, 187, 257-274.

2 K. F. Kalz, R. Kraehnert, M. Dvoyashkin, R. Dittmeyer, R. Gläser, U. Krewer, K. Reuter and J. D. Grunwaldt, ChemCatChem, 2017, 9, 17-29.

3 J. Niemantsverdriet, A. Engelen, A. de Jong, W. Wieldraaijer and G. Kramer, Appl. Surf. Sci., 1999, 144, 366-374.

4 J. Serafin, A. Liu and S. Seyedmonir, J. Mol. Catal. A: Chem., 1998, 131, 157-168.

5 P. C. Thüne and J. H. Niemantsverdriet, Surf. Sci., 2009, 603, 1756-1762. 
6 I. E. Wachs, Surf. Sci., 2003, 544, 1-4.

7 K. W. Kolasinski, Surface science: foundations of catalysis and nanoscience, John Wiley \& Sons, 2012.

8 J. Hudson, Surface science: an introduction, Elsevier, 2013.

9 H. Lüth, Solid surfaces, interfaces and thin films, Springer, 2001.

10 G. Benedek and J. P. Toennies, Helium Atom Scattering Spectroscopy of Surface Phonons, Springer, Berlin, 2012.

11 V. Aquilanti, D. Cappelletti, F. Pirani, L. Y. Rusin, M. B. Sevryuk and J. P. Toennies, J. Phys. Chem., 1991, 95, 8248-8255.

12 J. P. Toennies, J. Phys.: Condens. Matter, 1993, 5, A25-A40.

13 P. Nieto, E. Pijper, D. Barredo, G. Laurent, R. A. Olsen, E.-J. Baerends, G.-J. Kroes and D. Farías, Science, 2006, 312, 86-89.

14 D. Maccariello, D. Campi, A. Al Taleb, G. Benedek, D. Farías, M. Bernasconi and R. Miranda, Carbon, 2015, 93, 1-10.

15 G. A. Somorjai, J. Phys. Chem., 1990, 94, 1013-1023.

16 H. Bonzel, Surf. Sci., 1977, 68, 236-258.

17 G. A. Somorjai, Surf. Sci., 1994, 299, 849-866.

18 M. Sterrer and H.-J. Freund, Catal. Lett., 2013, 143, 375-385.

19 I. Langmuir, J. Am. Chem. Soc., 1918, 40, 1361-1403.

20 G. Ertl, Angew. Chem., Int. Ed., 2008, 47, 3524-3535.

21 G. Ertl, Angew. Chem., Int. Ed. Engl., 1990, 29, 1219-1227.

22 A. Politano and G. Chiarello, J. Phys. Chem. C, 2011, 115, 13541-13553.

23 H. Ibach, Surf. Sci., 1994, 299, 116-128.

24 H. Steininger, S. Lehwald and H. Ibach, Surf. Sci., 1982, 123, 1-17.

25 M. F. Bertino, S. Miret-Artes and J. P. Toennies, Chem. Phys. Lett., 1998, 287, 663-670.

26 P. Brault, H. Range, J. P. Toennies and C. Wöll, Z. Phys. Chem., 1997, 198, 1-17.

27 J. Braun, J. P. Toennies and G. Witte, Surf. Sci., 1995, 340, 265-280.

28 L. W. Bruch, A. Glebov, J. P. Toennies and H. Weiss, J. Chem. Phys., 1995, 103, 5109-5120.

29 A. P. Graham, M. F. Bertino, F. Hofmann and J. P. Toennies, J. Chem. Soc., Faraday Trans., 1996, 92, 4749-4757.

30 A. P. Graham, A. Menzel and J. P. Toennies, J. Chem. Phys., 1999, 111, 1169-1174.

31 A. P. Graham and J. P. Toennies, J. Chem. Phys., 2003, 118, 2879-2885.

32 F. Hofmann, U. Svenson and J. P. Toennies, Surf. Sci., 1997, 371, 169-182.

33 D. Farías and K. H. Rieder, Rep. Prog. Phys., 1998, 61, 1575-1664.

34 D. Farías, M. Patting and K. H. Rieder, J. Chem. Phys., 2002, 117, 1797-1803.

35 D. Farías, P. Schilbe, M. Patting and K. H. Rieder, J. Chem. Phys., 1999, 110, 559-569.

36 D. Farías, H. Troger, M. Patting and K. H. Rieder, Surf. Sci., 1996, 352, 155-160.
37 R. Apel, D. Farías, H. Troger and K. H. Rieder, Surf. Sci., 1995, 331, 57-61.

38 A. G. C. Ros, J.-S. McEwen and P. Gaspard, Phys. Rev. E: Stat., Nonlinear, Soft Matter Phys., 2011, 83, 021604.

39 H. Arnolds, Prog. Surf. Sci., 2011, 86, 1-40.

40 Y. Morikawa, J. J. Mortensen, B. Hammer and J. K. Nørskov, Surf. Sci., 1997, 386, 67-72.

41 L. Grill, J. Phys.: Condens. Matter, 2010, 22, 084023.

42 N. Pavliček and L. Gross, Nat. Rev. Chem., 2017, 1, 1-11.

43 J. Wintterlin, J. Trost, S. Renisch, R. Schuster, T. Zambelli and G. Ertl, Surf. Sci., 1997, 394, 159-169.

44 T. Duchoň, J. Hackl, J. Höcker, K. Veltruská, V. Matolín, J. Falta, S. Cramm, S. Nemšák, C. M. Schneider and J. I. Flege, Ultramicroscopy, 2017, 183, 84-88.

45 M. Bowker, R. A. Bennett and I. Z. Jones, Top. Catal., 2004, 28, 25-30.

46 A. F. Lee, D. E. Gawthrope, N. J. Hart and K. Wilson, Surf. Sci., 2004, 548, 200-208.

47 J. Kim, W. H. Doh, H. Kondoh, K. Mase, J.-J. Gallet, F. Bournel, B. S. Mun and J. Y. Park, J. Electron Spectrosc. Relat. Phenom., 2020, 238, 146857.

48 M. Favaro, J. Yang, S. Nappini, E. Magnano, F. M. Toma, E. J. Crumlin, J. Yano and I. D. Sharp, J. Am. Chem. Soc., 2017, 139, 8960-8970.

49 S. Nappini, A. Matruglio, D. Naumenko, S. Dal Zilio, F. Bondino, M. Lazzarino and E. Magnano, Nanoscale, 2017, 9, 4456-4466.

50 M. Amati, V. Bonanni, L. Braglia, F. Genuzio, L. Gregoratti, M. Kiskinova, A. Kolmakov, A. Locatelli, E. Magnano, A. A. Matruglio, T. O. Menteş, S. Nappini, P. Torelli and P. Zeller, J. Electron Spectrosc. Relat. Phenom., 2019, 146902, DOI: 10.1016/j.elspec.2019.146902.

51 M. Fracchia, P. Ghigna, T. Pozzi, U. Anselmi Tamburini, V. Colombo, L. Braglia and P. Torelli, J. Phys. Chem. Lett., 2020, 11, 3589-3593.

52 P. Stoltze and J. Nørskov, Phys. Rev. Lett., 1985, 55, 2502.

53 H. Oosterbeek, Phys. Chem. Chem. Phys., 2007, 9, 3570-3576.

54 K. Reuter and H. Metiu, Handbook of Materials Modeling: Applications: Current and Emerging Materials, 2020, pp. 1309-1319.

55 O. Mamun, K. T. Winther, J. R. Boes and T. Bligaard, Sci. Data, 2019, 6, 1-9.

56 J. M. Kweun, C. Li, Y. Zheng, M. Cho, Y. Y. Kim and K. Cho, Appl. Surf. Sci., 2016, 370, 279-290.

57 T. Hu, M. Hu, B. Gao, W. Li and X. Wang, J. Phys. Chem. C, 2018, 122, 18501-18509.

58 M. G. Vergniory, L. Elcoro, C. Felser, N. Regnault, B. A. Bernevig and Z. Wang, Nature, 2019, 566, 480-485.

59 M. Dion, H. Rydberg, E. Schröder, D. C. Langreth and B. I. Lundqvist, Phys. Rev. Lett., 2004, 92, 246401.

60 S. Grimme, J. Comput. Chem., 2006, 27, 1787-1799.

61 D. W. Boukhvalov, Y. W. Son and R. S. Ruoff, ACS Catal., 2014, 4, 2016-2021.

62 C. Stampfl, M. V. Ganduglia-Pirovano, K. Reuter and M. Scheffler, Surf. Sci., 2002, 500, 368-394. 
63 S. Heiden, D. Usvyat and P. Saalfrank, J. Phys. Chem. C, 2019, 123, 6675-6684.

64 T. Hirai, M. Okoshi, A. Ishikawa and H. Nakai, Surf. Sci., 2019, 686, 58-62.

65 P. Miro, M. Audiffred and T. Heine, Chem. Soc. Rev., 2014, 43, 6537-6554.

66 A. K. Geim, Rev. Mod. Phys., 2011, 83, 851-862.

67 K. S. Novoselov, Rev. Mod. Phys., 2011, 83, 837-849.

68 M. S. Vitiello, JPhys Mater., 2019, 3, 014008.

69 L. Viti, D. G. Purdie, A. Lombardo, A. C. Ferrari and M. S. Vitiello, Nano Lett., 2020, 20, 3169-3177.

70 M. Vanni, M. Serrano-Ruiz, F. Telesio, S. Heun, M. Banchelli, P. Matteini, A. M. Mio, G. Nicotra, C. Spinella, S. Caporali, A. Giaccherini, F. D’Acapito, M. Caporali and M. Peruzzini, Chem. Mater., 2019, 31, 5075-5080.

71 A. Al Taleb, G. Anemone, R. Miranda and D. Farías, 2D Mater., 2018, 5, 045002.

72 E. Plummer, R. Matzdorf, A. Melechko, J. Pierce and J. Zhang, Surf. Sci., 2002, 500, 1-27.

73 H. K. Jeong, H. J. Noh, J. Y. Kim, L. Colakerol, P. A. Glans, M. H. Jin, K. E. Smith and Y. H. Lee, Phys. Rev. Lett., 2009, 102, 099701.

74 A. P. Kauling, A. T. Seefeldt, D. P. Pisoni, R. C. Pradeep, R. Bentini, R. V. Oliveira, K. S. Novoselov and A. H. Castro Neto, Adv. Mater., 2018, 30, 1803784.

75 N. M. Marković and P. N. Ross, Surf. Sci. Rep., 2002, 45, 117-229.

76 B. Braunchweig, D. Hibbitts, M. Neurock and A. Wieckowski, Catal. Today, 2013, 202, 197-209.

77 S. M. Tan, C. K. Chua, D. Sedmidubský, Z. B. Sofer and M. Pumera, Phys. Chem. Chem. Phys., 2016, 18, 1699-1711.

78 M. I. Zappia, G. Bianca, S. Bellani, M. Serri, L. Najafi, R. OropesaNuñez, B. Martín-García, D. Bouša, D. Sedmidubský, V. Pellegrini, Z. Sofer, A. Cupolillo and F. Bonaccorso, Adv. Funct. Mater., 2020, 30, 1909572.

79 Y. Wu, D. Zhang, K. Lee, G. S. Duesberg, A. Syrlybekov, X. Liu, M. Abid, M. Abid, Y. Liu, L. Zhang, C. Ó. Coileáin, H. Xu, J. Cho, M. Choi, B. S. Chun, H. Wang, H. Liu and H. C. Wu, Adv. Mater. Technol., 2017, 2, 1600197.

80 O. A. Balitskii, V. P. Savchyn and V. O. Yukhymchuk, Semicond. Sci. Technol., 2002, 17, L1-L4.

81 T. E. Beechem, B. M. Kowalski, M. T. Brumbach, A. E. McDonald, C. D. Spataru, S. W. Howell, T. Ohta, J. A. Pask and N. G. Kalugin, Appl. Phys. Lett., 2015, 107, 173103.

82 A. Bergeron, J. Ibrahim, R. Leonelli and S. Francoeur, Appl. Phys. Lett., 2017, 110, 241901.

83 E. Filippo, M. Siciliano, A. Genga, G. Micocci, A. Tepore and T. Siciliano, Mater. Res. Bull., 2013, 48, 1741-1744.

84 H. Iwakuro, C. Tatsuyama and S. Ichimura, Jpn. J. Appl. Phys., 1982, 21, 94.

85 B. M. Kowalski, N. Manz, D. Bethke, E. A. Shaner, A. Serov and N. G. Kalugin, Mater. Res. Express, 2019, 6, 085907.

86 M. Rahaman, R. D. Rodriguez, M. Monecke, S. A. Lopez-Rivera and D. R. T. Zahn, Semicond. Sci. Technol., 2017, 32, 105004.

87 T. Siciliano, M. Tepore, A. Genga, G. Micocci, M. Siciliano and A. Tepore, Vacuum, 2013, 92, 65-69.

88 N. K. Tovstyuk, J. Phys. Stud., 2004, 8, 47-54.
89 D. Pozo-Zamudio, S. Schwarz, J. Klein, R. Schofield, E. Chekhovich, O. Ceylan, E. Margapoti, A. Dmitriev, G. Lashkarev and D. Borisenko, 2015, arXiv:1506.05619.

90 D. Andres-Penares, A. Cros, J. P. Martínez-Pastor and J. F. Sánchez-Royo, Nanotechnology, 2017, 28, 175701.

91 Q. Zhao, R. Frisenda, P. Gant, D. Perez de Lara, C. Munuera, M. Garcia-Hernandez, Y. Niu, T. Wang, W. Jie and A. Castellanos-Gomez, Adv. Funct. Mater., 2018, 28, 1805304.

92 J. Susoma, J. Lahtinen, M. Kim, J. Riikonen and H. Lipsanen, AIP Adv., 2017, 7, 015014.

93 G. D’Olimpio, S. Nappini, M. Vorokhta, L. Lozzi, F. Genuzio, T. O. Menteș, V. Paolucci, B. Gürbulak, S. Duman, L. Ottaviano, A. Locatelli, F. Bondino, D. W. Boukhvalov and A. Politano, Adv. Funct. Mater., 2020, DOI: 10.1002/adfm.202005466.

94 J. Kim, S. M. Han and W. S. Yoo, J. Micro/Nanolithogr., MEMS, MOEMS, 2014, 13, 011205.

95 P. Borowicz, J. Spectrosc., 2016, 2016, 1617063.

96 L. Shi, Q. Zhou, Y. Zhao, Y. Ouyang, C. Ling, Q. Li and J. Wang, J. Phys. Chem. Lett., 2017, 8, 4368-4373.

97 Y. Ni, H. Wu, C. Huang, M. Mao, Z. Wang and X. Cheng, J. Cryst. Growth, 2013, 381, 10-14.

98 J. Greeley, T. F. Jaramillo, J. Bonde, I. Chorkendorff and J. K. Nørskov, Nat. Mater., 2006, 5, 909-913.

99 E. Petroni, E. Lago, S. Bellani, D. W. Boukhvalov, A. Politano, B. Gürbulak, S. Duman, M. Prato, S. Gentiluomo, R. OropesaNuñez, J. K. Panda, P. S. Toth, A. E. Del Rio Castillo, V. Pellegrini and F. Bonaccorso, Small, 2018, 14, 1800749.

100 S. M. Tan, C. K. Chua, D. Sedmidubský, Z. Sofer and M. Pumera, Phys. Chem. Chem. Phys., 2016, 18, 1699-1711.

101 Q. Yang, G. Li, K. Manna, F. Fan, C. Felser and Y. Sun, Adv. Mater., 2020, 32, 1908518.

102 A. Politano, G. Chiarello, Z. Li, V. Fabio, L. Wang, L. Guo, X. Chen and D. W. Boukhvalov, Adv. Funct. Mater., 2018, 28, 1800511.

103 C. R. Rajamathi, U. Gupta, N. Kumar, H. Yang, Y. Sun, V. Suss, C. Shekhar, M. Schmidt, H. Blumtritt, P. Werner, B. Yan, S. Parkin, C. Felser and C. N. R. Rao, Adv. Mater., 2017, 29, 1606202.

104 G. Li, C. Fu, W. Shi, L. Jiao, J. Wu, Q. Yang, R. Saha, M. E. Kamminga, A. K. Srivastava, E. Liu, A. N. Yazdani, N. Kumar, J. Zhang, G. R. Blake, X. Liu, M. Fahlman, S. Wirth, G. Auffermann, J. Gooth, S. Parkin, V. Madhavan, X. Feng, Y. Sun and C. Felser, Angew. Chem., Int. Ed., 2019, 58, 13107-13112.

105 G. Li, Q. Xu, W. Shi, C. Fu, L. Jiao, M. E. Kamminga, M. Yu, H. Tüysüz, N. Kumar and V. Süß, Sci. Adv., 2019, 5, eaaw9867. 106 G. Li and C. Felser, Appl. Phys. Lett., 2020, 116, 070501.

107 Z. P. Xiang, H. Q. Deng, P. Peljo, Z. Y. Fu, S. L. Wang, D. Mandler, G. Q. Sun and Z. X. Liang, Angew. Chem., Int. Ed., 2018, 130, 3522-3526.

108 J. Greeley, I. Stephens, A. Bondarenko, T. P. Johansson, H. A. Hansen, T. Jaramillo, J. Rossmeisl, I. Chorkendorff and J. K. Nørskov, Nat. Chem., 2009, 1, 552.

109 Y. Wu, L.-L. Wang, E. Mun, D. D. Johnson, D. Mou, L. Huang, Y. Lee, S. L. Bud'ko, P. C. Canfield and A. Kaminski, Nat. Phys., 2016, 12, 667-671. 
110 V. R. Stamenković, B. S. Mun, K. J. J. Mayrhofer, P. N. Ross and N. M. Marković, J. Am. Chem. Soc., 2006, 128, 8813-8819.

111 D. F. van der Vliet, C. Wang, D. Li, A. P. Paulikas, J. Greeley, R. B. Rankin, D. Strmcnik, D. Tripkovic, N. M. Marković and V. R. Stamenković, Angew. Chem., Int. Ed., 2012, 124, 3193-3196.

112 Z. Yang, J. Wang and X. Yu, Chem. Phys. Lett., 2010, 499, 83-88.

113 D. W. Boukhvalov, A. Marchionni, J. Filippi, R. Edla, S. Nappini, J. Fuji, C. N. Kuo, G. D’Olimpio, L. Ottaviano, C. S. Lue, P. Torelli, F. Vizza and A. Politano, J. Mater. Chem. A, 2020, 8, 2349-2355.

114 G. D’Olimpio, D. W. Boukhvalov, J. Fujii, P. Torelli, A. Marchionni, J. Filippi, C.-N. Kuo, R. Edla, L. Ottaviano and C. S. Lue, Appl. Surf. Sci., 2020, 145925.

115 Y. Jugnet, D. Loffreda, C. L. Dupont, F. O. Delbecq, E. Ehret, F. J. Cadete Santos Aires, B. S. Mun, F. Aksoy Akgul and Z. Liu, J. Phys. Chem. Lett., 2012, 3, 3707-3714.

116 I. G. Casella and E. Desimoni, Electroanalysis, 1996, 8, 447-453.

117 K. I. B. Eguiluz, G. R. P. Malpass, M. M. S. Pupo, G. R. Salazar-Banda and L. A. Avaca, Energy Fuels, 2010, 24, 4012-4024.

118 M. A. Henderson, Surf. Sci. Rep., 2011, 66, 185-297.

119 L. Mino, A. Zecchina, G. Martra, A. M. Rossi and G. Spoto, Appl. Catal., B, 2016, 196, 135-141.

120 H. Cheng, J. Hou, O. Takeda, X.-M. Guo and H. Zhu, J. Mater. Chem. A, 2015, 3, 11006-11013.

121 N. Khalid, Z. Israr, M. Tahir and T. Iqbal, Int. J. Hydrogen Energy, 2020, 45, 8479-8489.

122 W. Hou and S. B. Cronin, Adv. Funct. Mater., 2013, 23, 1612-1619.

123 W. Wang, G. Li, D. Xia, T. An, H. Zhao and P. K. Wong, Environ. Sci.: Nano, 2017, 4, 782-799.

124 P. Prasannalakshmi and N. Shanmugam, Mater. Sci. Semicond. Process., 2017, 61, 114-124.

125 D. Bahnemann, Sol. Energy, 2004, 77, 445-459.

126 M. Landmann, E. Rauls and W. G. Schmidt, J. Phys.: Condens. Matter, 2012, 24, 6.

127 B. Ohtani, Catalysts, 2013, 3, 942-953.

128 Y. Li, C. Gao, R. Long and Y. Xiong, Mater. Today Chem., 2019, 11, 197-216.

129 Z. Xie, Y.-P. Peng, L. Yu, C. Xing, M. Qiu, J. Hu and H. Zhang, Sol. RRL, 2020, 4, 1900400.

130 W. Peng, Y. Li, F. Zhang, G. Zhang and X. Fan, Ind. Eng. Chem. Res., 2017, 56, 4611-4626.

131 B. Luo, G. Liu and L. Wang, Nanoscale, 2016, 8, 6904-6920.

132 C. A. Walenta, M. Tschurl and U. Heiz, J. Phys.: Condens. Matter, 2019, 31, ab351a.

133 C. A. Walenta, C. Courtois, S. L. Kollmannsberger, M. Eder, M. Tschurl and U. Heiz, ACS Catal., 2020, 10, 4080-4091.

134 X. Yang, Z. Chen, J. Xu, H. Tang, K. Chen and Y. Jiang, ACS Appl. Mater. Interfaces, 2015, 7, 15285-15293.

135 A. Alagarasi, P. U. Rajalakshmi, K. Shanthi and P. Selvam, Catal. Today, 2018, 309, 202-211.
136 J. Xiong, J. Di, J. Xia, W. Zhu and H. Li, Adv. Funct. Mater., 2018, 28, 1801983.

137 M. Wang, L. Cai, Y. Wang, F. Zhou, K. Xu, X. Tao and Y. Chai, J. Am. Chem. Soc., 2017, 139, 4144-4151.

138 L. Jing, Y. Xu, Z. Chen, M. He, M. Xie, J. Liu, H. Xu, S. Huang and H. Li, ACS Sustainable Chem. Eng., 2018, 6, 5132-5141.

139 F. J. Zhang, X. Li, X. Y. Sun, C. Kong, W. J. Xie, Z. Li and J. Liu, Appl. Surf. Sci., 2019, 487, 734-742.

140 D. Yim, F. Raza, J. H. Park, J. H. Lee, H. I. Kim, J. K. Yang, I. J. Hwang and J. H. Kim, ACS Appl. Mater. Interfaces, 2019, 11, 36960-36969.

141 K. K. Patra, M. K. Ghosalya, H. Bajpai, S. Raj and C. S. Gopinath, J. Phys. Chem. C, 2019, 123, 21685-21693.

142 H. Cheng, X. Qian, Y. Kuwahara, K. Mori and H. Yamashita, Adv. Mater., 2015, 27, 4616-4621.

143 L. E. Ocola, Y. Wang, R. Divan and J. Chen, Sensors, 2019, 19, 2061.

144 N. Barsan and U. Weimar, J. Electroceram., 2001, 7, 143-167. 145 R. Kumar, N. Goel, M. Hojamberdiev and M. Kumar, Sens. Actuators, A, 2020, 303, 111875.

146 Q. Li, Q. Zhou, L. Shi, Q. Chen and J. Wang, J. Mater. Chem. A, 2019, 7, 4291-4312.

147 Y. Guo, S. Zhou and J. Zhao, ChemNanoMat, 2020, 6, 838-849.

148 A. Shafique, A. Samad and Y.-H. Shin, Phys. Chem. Chem. Phys., 2017, 19, 20677-20683.

149 O. S. L. Camargo Moreira, W.-Y. Cheng, H.-R. Fuh, W.-C. Chien, W. Yan, H. Fei, H. Xu, D. Zhang, Y. Chen and Y. Zhao, ACS Sens., 2019, 4, 2546-2552.

150 X. Wang, Y. Liu, J. Dai, Q. Chen, X. Huang and W. Huang, Chem. - Eur. J., 2020, 26, 3870-3876.

151 A. S. Pawbake, A. Date, S. R. Jadkar and D. J. Late, ChemistrySelect, 2016, 1, 5380-5387.

152 M. Pawar, S. Kadam and D. J. Late, ChemistrySelect, 2017, 2, 4068-4075.

153 M. Chen, Z. Li, W. Li, C. Shan, W. Li, K. Li, G. Gu, Y. Feng, G. Zhong and L. Wei, Nanotechnology, 2018, 29, 455501.

154 V. Paolucci, G. D’Olimpio, C.-N. Kuo, C. S. Lue, D. W. Boukhvalov, C. Cantalini and A. Politano, ACS Appl. Mater. Interfaces, 2020, 12, 34362-34369.

155 P. Cox, R. Egdell, W. Flavell and R. Helbig, Vacuum, 1983, 33, 835-838.

156 C. Tortajada and A. K. Biswas, Curr. Opin. Environ. Sustainability, 2018, 34, 21-25.

157 J. Willet, K. Wetser, J. Vreeburg and H. H. Rijnaarts, Water Resources and Industry, 2019, 21, 100110.

158 A. Politano, G. Di Profio, E. Fontananova, V. Sanna, A. Cupolillo and E. Curcio, Desalination, 2019, 451, 192-199.

159 A. Politano, P. Argurio, G. Di Profio, V. Sanna, A. Cupolillo, S. Chakraborty, H. A. Arafat and E. Curcio, Adv. Mater., 2017, 29, 1603504.

160 L. Eykens, K. De Sitter, C. Dotremont, L. Pinoy and B. Van der Bruggen, Ind. Eng. Chem. Res., 2016, 55, 9333-9343.

161 F. Calise, F. L. Cappiello, R. Vanoli and M. Vicidomini, Appl. Energy, 2019, 253, 113575. 
162 E. Drioli, A. Ali and F. Macedonio, Desalination, 2015, 356, 56-84.

163 E. Gontarek, F. Macedonio, F. Militano, L. Giorno, M. Lieder, A. Politano, E. Drioli and A. Gugliuzza, Nanoscale, 2019, 11, 11521-11529.

164 F. Perreault, A. Fonseca de Faria and M. Elimelech, Chem. Soc. Rev., 2015, 44, 5861-5896.

165 T. Minato and T. Abe, Prog. Surf. Sci., 2017, 92, 240-280.

166 K. Iwaya, T. Ogawa, T. Minato, K. Miyoshi, J. Takeuchi, A. Kuwabara, H. Moriwake, Y. Kim and T. Hitosugi, Phys. Rev. Lett., 2013, 111, 126104.

167 S. Kobayashi, C. A. J. Fisher, T. Kato, Y. Ukyo, T. Hirayama and Y. Ikuhara, Nano Lett., 2016, 16, 5409-5414.
168 M. Kitta, M. Kohyama and H. Onishi, Appl. Phys. Lett., 2014, 105, 111606.

169 Y. Okada, Y. Ando, R. Shimizu, E. Minamitani, S. Shiraki, S. Watanabe and T. Hitosugi, Nat. Commun., 2017, 8, 15975.

170 L. Hong, L. Hu, J. W. Freeland, J. Cabana, S. Öğüt and R. F. Klie, J. Phys. Chem. C, 2019, 123, 8851-8858.

171 H. Tatsumi, A. Sasahara and M. Tomitori, J. Phys. Chem. C, 2012, 116, 13688-13692.

172 S. Krischok, J. Schaefer, O. Höfft and V. Kempter, Surf. Interface Anal., 2005, 37, 83-89.

173 V. Ageev and S. Solov'ev, Phys. Solid State, 2000, 42, 2159-2163.

174 R. Hausbrand, D. Becker and W. Jaegermann, Prog. Solid State Chem., 2014, 42, 175-183. 